\title{
Intrathoracic anastomotic leakage after gastroesophageal cancer resection is associated with increased risk of recurrence
}

\author{
Steen C. Kofoed, MD, PhD, ${ }^{a}$ Dan Calatayud, MD, ${ }^{\mathrm{a}}$ Lone S. Jensen, MD, PhD, ${ }^{b}$ Frederik Helgstrand, MD, ${ }^{\mathrm{a}}$ \\ Michael P. Achiam, MD, PhD, ${ }^{a}$ Pieter De Heer, MD, PhD, ${ }^{a}$ and Lars B. Svendsen, MD, PhD, ${ }^{a}$ on behalf of \\ the Danish Esophageal, Cardia and Stomach Cancer Group
}

\begin{abstract}
Objective: Intrathoracic anastomotic leakage after intended curative resection for cancer in the esophagus or gastroesophageal junction has a negative impact on long-term survival. The aim of this study was to investigate whether an anastomotic leakage was associated with an increased recurrence rate.

Methods: This nationwide study included consecutively collected data on patients undergoing curative surgical resection with intrathoracic anastomosis, alive 8 weeks postoperatively, between 2003 and 2011. Patients with incomplete resection, or metastatic disease intraoperatively, were excluded. Only biopsy-proven recurrences were accepted.
\end{abstract}

Results: In total, 1085 patients were included. The frequency of anastomotic leakage was $8.6 \%$. The median follow-up time was 29 months (interquartile range [IQR]: 13-58 months). Overall, 369 (34\%) patients had disease recurrence, of which 346 patients died of recurrent gastroesophageal carcinoma. Twenty-three patients were alive with recurrence at the censoring date. In the study period, 333 patients died without signs of recurrent disease.

The overall median time to recurrence was 66 weeks (IQR: 38-109 weeks). Distant metastases were found in $267(25 \%)$, and local disease recurrence in $102(9 \%)$ patients. Overall, 5-year disease-free survival in patients with leakage was $27 \%$, versus $39 \%$ in those without leakage $(P=.017)$. Anastomotic leakage was independently associated with higher risk of recurrence (hazard ratio $[\mathrm{HR}]=1.63 ; 95 \%$ confidence interval $[\mathrm{CI}]: 1.17-2.29, P=.004)$ and all-cause mortality $(\mathrm{HR}=1.57 ; 95 \% \mathrm{CI}: 1.23-2.05, P<.0001)$.

Conclusions: Intrathoracic anastomotic leakage increased the risk of recurrence in patients who underwent curative gastroesophageal cancer resection. ( $\mathrm{J}$ Thorac Cardiovasc Surg 2015;150:42-8)

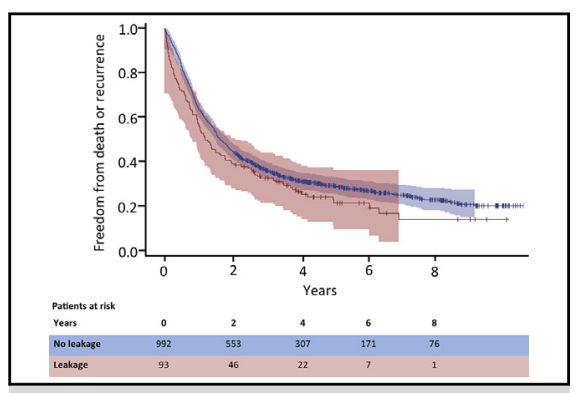

Survival, with and without leakage, after esophagectomy with intrathoracic anastomosis.

\section{Central Message}

We found an increased risk of recurrence after intrathoracic anastomotic leakage, after gastroesophageal cancer resection.

\section{Perspective}

Anastomotic leakage after esophagectomy for a malignant tumor has a negative effect on the patient through an increased risk of morbidity and mortality. We demonstrate that leakage additionally increases the risk of recurrence. These findings should direct more attention to identification of factors that may contribute to anastomotic leakage in patients undergoing esophagectomy with intrathoracic anastomosis.

See Editorial Commentary page 49.
Surgery is a potential curative treatment of cancer in the esophagus or gastroesophageal junction. Long-term survivors who had definitive chemoradiation, even though they are few, make it an alternative to surgical resection. ${ }^{1,2}$ One of the most feared surgical complications is

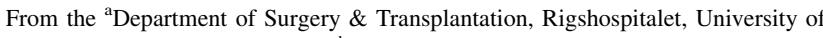
Copenhagen, Copenhagen; and ${ }^{\mathrm{b}}$ Department of Surgery, Aarhus Hospital, University of Aarhus, Aarhus, Denmark.

Received for publication Aug 29, 2014; revisions received April 7, 2015; accepted for publication April 11, 2015; available ahead of print May 16, 2015

Address for reprints: Steen C. Kofoed, MD, PhD, Department of Surgery \& Transplantation 2-12-2, Rigshospitalet, Copenhagen University Hospital, Blegdamsvej 9, DK-2100 Copenhagen, Denmark (E-mail: Steen.Christian.Kofoed@ regionh.dk).

0022-5223/\$36.00

Copyright (c) 2015 by The American Association for Thoracic Surgery

http://dx.doi.org/10.1016/j.jtcvs.2015.04.030
}

anastomotic leakage, which occurs in up to $10 \%$ of these patients. $^{3-9}$ Anastomotic leakage exerts an obvious negative influence by increasing the risk of immediate morbidity and mortality, but many believe that leakage additionally increases the risk of recurrence. ${ }^{10}$ These studies demonstrated a trend, but they failed to show a clear and significant negative effect on long-term survival, presumably because of the small patient cohorts and the inconsistent definitions of leakage.

In contrast, we recently demonstrated a robust negative impact of anastomotic leakage on long-term survival in patients alive 8 weeks after curative gastroesophageal cancer resection with intrathoracic anastomosis, in a large, nationwide study. ${ }^{11}$ Whether this increased long-term mortality after an intrathoracic anastomotic leakage can be explained by an increased frequency of cancer recurrence is yet to be 


\section{Abbreviations and Acronyms \\ $\mathrm{CI}=$ confidence interval \\ $\mathrm{HR}=$ hazard ratio \\ $\mathrm{IQR}=$ interquartile range}

elucidated. A large study of 8589 patients alive 120 days after curative resection for colonic cancer demonstrated that patients with anastomotic leakage had significantly increased rates of distant recurrence and long-term allcause mortality, compared with patients without anastomotic leakage. ${ }^{12}$ Our hypothesis is that patients surviving an anastomotic leakage after curative resection for cancer in the esophagus, or at the gastroesophageal junction, with intrathoracic anastomosis have an increased risk of cancer recurrence.

\section{METHODS \\ Patients}

The present patient cohort and the surgical procedures used in the current study have been described previously. ${ }^{11}$ Analyses were based on data from the Danish Esophageal, Cardia and Stomach Cancer Database. From June 1, 2003 onward, all consecutive patients undergoing curative surgical resection for gastroesophageal cancer (either in the esophagus or at the gastroesophageal junction [Siewert type 1, 2, or 3]) in Denmark have been recorded prospectively in a national database. Information recorded includes: clinical data (age, gender, smoking, alcohol consumption, comorbidity, American Society of Anesthesiologists score, preoperative tumor stage); operative data (surgical approach, type of surgical procedure); pathology (tumor histology and resection margins); and major postoperative complications.

Only patients undergoing curative surgical resection with an intrathoracic anastomosis, treated between June 1, 2003 and December 31, 2011, were included in the study. Patients who underwent gastrectomy (Siewerts type 3), had an incomplete (microscopically [R1] or macroscopically [R2] remaining cancer in the resected specimen) surgical resection, or had metastatic disease intraoperatively were excluded from the study. Time zero for this study was 8 weeks after esophagectomy; patients who died or experienced a recurrence before 8 weeks were excluded (Figure 1).

\section{Surgical Approach}

Four centers in Denmark (population: 5.6 million) are certified to perform gastroesophageal cancer surgery. The following standard surgical technique was used: Tumors located in the esophagus, or at the gastroesophageal junction (Siewerts type 1 or 2), were resected, using the Ivor Lewis procedure consistently throughout the study period; a 2-phase abdominal and right chest approach was used, with subtotal esophagectomy followed by gastric pull-up and a stapled gastroesophageal anastomosis. A 2-field lymphadenectomy with D1+ resection in the abdomen, extended with dissection of the truncal celiac nodes and en-bloc mediastinal lymphadenectomy, including paraesophageal and subcarinal lymph nodes, was mandatory. Cervical lymphadenectomy was not performed, and the lines of resection were placed as far away from the tumor as possible, and $\geq 6 \mathrm{~cm}$ from both ends.

Denmark has a long tradition of performing esophageal resection through a right-sided thoracotomy with intrathoracic anastomosis. A neck anastomosis is performed only if the tumor is very proximally located in the esophagus. In all centers, experienced pathologists, who are subspecialists in upper-gastrointestinal cancers, performed the history-pathologic examination of the resected specimens.

\section{Oncologic Treatment}

Since January 2009, patients with adenocarcinoma have received perioperative chemotherapy consisting of 3 preoperative cycles of epirubicin (Ellence, Actavis, Dublin, Ireland), oxaliplatin (Eloxatin; Sanofi, Paris, France); and capecitabine (Xeloda; Roche, Basel, Switzerland), followed by surgery after 3 weeks. After recovery, the patient received 3 postoperative cycles. Patients with squamous cell carcinoma received preoperative concomitant chemoradiation ( 25 fractions with 2 Gy per fraction), and 2 cycles of cisplatin (Platinol; Bristol-Myers Squibb, New York, NY) and fluorouracil (5-FU; Accord Healthcare, Durham, NC), followed by surgery after 8 weeks.

\section{Anastomotic Leakage}

Anastomotic leakage was defined as an esophagogastric, anastomotic leak recognized by 1 of the following methods: (1) radiologically, using a water-soluble radiograph contrast medium at day 7 postoperatively, or earlier if suspected; (2) using an acute computed tomography scan performed because of clinical signs of leakage (fever; chest pain; saliva or gastrointestinal content through chest drain); (3) via signs of conduit necrosis (gastrostomy line) or anastomotic dehiscence by upper-gastrointestinal endoscopy in critically ill patients; and (4) from evidence of tracheoesophageal fistula. Patients with contained leaks were categorized as having a leak.

Patients with leakage who underwent thoracotomy were classified as requiring surgical reintervention. Those treated with stenting and/or percutaneous drainage were classified as requiring conservative reintervention. We have previously shown that patients with an asymptomatic leak carry the same risk of death as those with symptomatic leaks. ${ }^{11}$

\section{Disease Recurrence}

Patients were followed for 2 years postoperatively with clinical examination. If recurrence was suspected based on clinical findings, a computed tomography or positron emission tomography scan was scheduled. All cases of disease recurrence were verified histologically, using biopsies, and information on disease recurrence was based on data extracted from the Danish Pathology Registry on February 5, 2014. The registry, established in 1997, contains histopathologic information on all biopsies and resected material from patients throughout all of Denmark.

Recurrent disease was classified as local or distant recurrence. Local recurrence was defined as cancer at the anastomotic line, in the gastric conduit, in the mediastinum, or around the celiac trunk in the abdomen. Distant recurrence was defined as metastases in a solid organ, or within the peritoneal or pleural cavity, and patients with both local and distant disease recurrence were classified as having distant recurrence.

\section{Statistical Analysis}

Disease-free survival was defined from 8 weeks after esophagectomy until the date of either disease recurrence (date of positive biopsy) or death. February 5, 2014 was the censoring date for investigation of the pathology registry, and the censoring date for survival.

Comparison of survival time, stratified by anastomotic leakage or no leakage, was conducted using the Kaplan-Meier method, and the logrank test was used to evaluate the statistical significance of the differences. Categoric data were compared using $\chi^{2}$ analysis or the Fisher exact test. Continuous data are shown as mean $\pm \mathrm{SD}$, or as median and interquartile range (IQR); they were compared using the Mann-Whitney $U$ test.

Cox multiple regression analysis was used to identify independent risk factors for disease recurrence and death. Variables with $P$ values $<.2$, found in univariate analysis comparing patients with or without disease recurrence (gender, age, postoperative tumor stage, lymph node status, histology, oncologic therapy, and anastomotic leakage), were entered into the regression model as forced entry. Patients with missing values were excluded from the regression analysis.

Risk was given as hazard ratios (HRs) with $95 \%$ confidence intervals (CIs). All analyses were conducted using IBM SPSS, version 19.0, 
1296 patients undergoing gastro-esophageal cancer resection with intrathoracic anastomosis

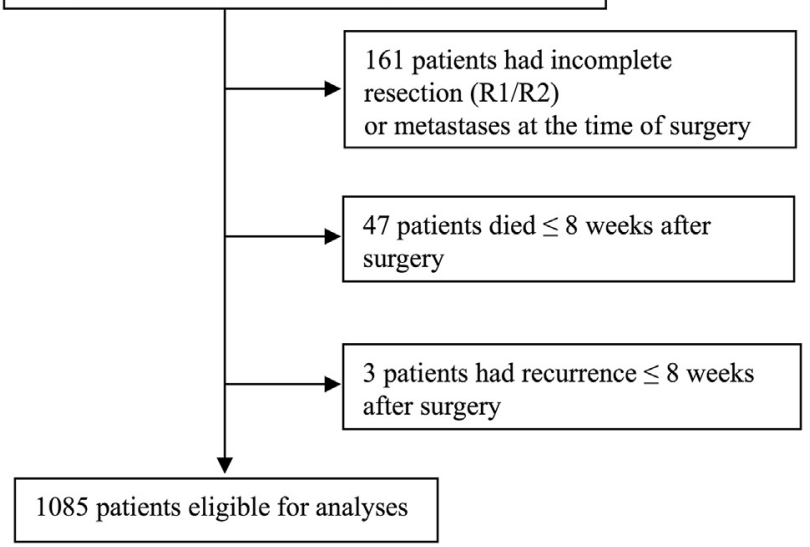

FIGURE 1. Patients included in the study.

statistical software (SPSS, Chicago, Ill). The Danish Data Protection Agency approved the collection and processing of data in this study (2012-331-0068 and 2007-58-0015).

\section{RESULTS}

During the 9-year period, 1296 patients underwent intended curative gastroesophageal resection for a malignant tumor in the esophagus or at the gastroesophageal junction. After exclusion of patients, according to the previously mentioned criteria, a cohort of 1085 patients were found to be eligible for further analyses (Figure 1). The median age was 64 years (IQR: 58-70 years). The median followup time was 29 months (IQR: 13-58 months).

The incidence of anastomotic leakage was 93 of 1085 $(8.6 \%)$. Clinical and histopathologic differences between patients who developed disease recurrence and those who did not are shown in Table 1, and patients who developed anastomotic leakage and those who did not are shown in Table 2. Data on perioperative chemotherapy (adenocarcinoma) or preoperative chemoradiation (squamous cell carcinoma) was available in only 162 patients. Of patients who had a leak, $55 \%$ completed the second part of the perioperative program, compared with $80 \%$ of those who did not have a leak. As shown in Table 2, a total of 860 (79\%) patients were men, and the predominant histology was adenocarcinoma (865 patients; $80 \%$ ).

\section{Pattern of Recurrence}

Overall, 369 (34\%) patients had biopsy-verified disease recurrence in the study period; of these, 346 patients died of recurrent gastroesophageal carcinoma, whereas 23 were alive with recurrence at the censoring date. In the study period, 333 patients died without signs of recurrent disease. The overall median time to recurrence was
66 weeks (IQR: 38-109 weeks). At the censoring date, $382(35 \%)$ disease-free patients were alive.

Distant metastases were found in $267(25 \%)$ patients, and the distribution of locations was as follows: 59 liver; 51 peritoneal or pleural carcinosis; 37 cervical lymph nodes; 29 skin; 21 retroperitoneal; 19 cerebral; 19 bone; 16 lungs; and 16 in various other locations. Local disease recurrence was seen in $102(9 \%)$ patients.

\section{Survival and Predictors of Recurrence or Death}

In patients with recurrence, the frequency of advanced tumor stage and positive node status were significantly higher, and the frequency of receiving oncologic treatment was significantly lower, compared with that in patients without recurrence (Table 1). In multivariate analysis, anastomotic leakage was independently associated with a higher risk of disease recurrence $(\mathrm{HR}=1.63 ; 95 \% \mathrm{CI}: 1.17-2.29$, $P=.004)$ as well as all-cause mortality $(\mathrm{HR}=1.57$; $95 \%$ CI: $1.23-2.05, P<.0001)$. Other variables that had significant influence on recurrence, found in multivariate analysis, were: final pathologic tumor stage (T3 or T4), and positive lymph node status. Variables that had significant influence on all-cause mortality, found in multivariate analysis, were: male gender, increasing age, final pathologic tumor stage (T3 or T4), and positive lymph node status (Table 1).

Overall, 5-year disease-free survival was significantly lower in patients with anastomotic leakage, compared with those without leakage $(P=.017$; Table 2 and Figure 2). Whether patients were treated with surgical reintervention, or conservatively, with stenting and/or drainage, the overall survival was unaffected $(P=.532$; Figure 3$)$. The numbers of recurrences in the 2 reintervention groups were not different $(P=.129$; Table 3$)$.

\section{DISCUSSION}

The present study (nationwide data collected from patients undergoing curative resections of esophageal or gastroesophageal malignant tumors with intrathoracic anastomosis) demonstrates a higher risk of cancer recurrence in patients who experienced anastomotic leakage postoperatively. In the same cohort, we have shown previously that overall survival in patients with anastomotic leakage is lower, compared with those with an uneventful recovery. ${ }^{11}$ In addition, the present study demonstrates a lower diseasefree survival rate after anastomotic leakage in radically resected patients who do not have signs of residual cancer, alive 8 weeks after the primary surgery.

The novel finding that anastomotic leakage is an independent risk factor of cancer recurrence may, perhaps, explain the excess mortality seen in our cohort, as well as in several other studies regarding long-term outcome and anastomotic complications. However, owing to the observational design of our study, we can examine only the relationship between 
TABLE 1. Clinical and histopathologic characteristics in patients with, versus without, disease recurrence

\begin{tabular}{|c|c|c|c|c|c|c|c|c|c|}
\hline & $\begin{array}{l}\text { Recurrence } \\
(\mathbf{n}=369)\end{array}$ & $\begin{array}{l}\text { No recurrence } \\
\quad(n=716)\end{array}$ & $\begin{array}{l}\text { Missing } \\
\text { (n) }\end{array}$ & HR & $\begin{array}{c}\text { Risk of recurrence } \\
(\mathbf{9 5} \% \mathbf{C I})\end{array}$ & $P$ value & HR & $\begin{array}{l}\text { Mortality } \\
(\mathbf{9 5} \% \text { CI })\end{array}$ & $P$ value \\
\hline Gender & & & 0 & & & & & & \\
\hline Female & $65(18)$ & $160(22)$ & & 1 & & .110 & 1 & & \\
\hline Male & $304(82)$ & $556(78)$ & & 1.25 & $0.95-1.65$ & & 1.29 & $1.06-1.58$ & .013 \\
\hline Age $(y)$, mean $( \pm$ SD $)$ & $63( \pm 9)$ & $63( \pm 9)$ & & 1.01 & $0.99-1.02$ & .150 & 1.03 & $1.02-1.03$ & $<.0001$ \\
\hline Smoking & & & 111 & & & & & & \\
\hline Nonsmoker & $155(42)$ & 329 (46) & & & & & & & \\
\hline Smoker & $173(47)$ & $317(44)$ & & & & & & & \\
\hline $\begin{array}{l}\text { Alcohol consumption (units per } \\
\text { wk) }\end{array}$ & & & 51 & & & & & & \\
\hline$<14 / 21$ & $301(82)$ & $596(83)$ & & & & & & & \\
\hline$>14 / 21$ & 45 (12) & $92(13)$ & & & & & & & \\
\hline ASA score & & & 6 & & & & & & \\
\hline $1+2$ & $282(76)$ & $546(76)$ & & & & & & & \\
\hline $3+4$ & $84(23)$ & $167(23)$ & & & & & & & \\
\hline Nodal yield & 20 (IQR: 15-28) & 20 (IQR: 13-26) & 1 & & & & & & \\
\hline Postoperative tumor stage & & & 5 & & & & & & \\
\hline T0 & $10(3)$ & $70(10)$ & & 1 & & & 1 & & \\
\hline $\mathrm{T} 1$ & $29(6)$ & $108(15)$ & & 1.07 & $0.52-2.23$ & .850 & 1.18 & $0.69-2.04$ & .544 \\
\hline $\mathrm{T} 2$ & $160(43)$ & $287(40)$ & & 1.50 & $0.77-2.95$ & .234 & 1.93 & $1.18-3.17$ & .009 \\
\hline $\mathrm{T} 3$ & $160(43)$ & $232(32)$ & & 1.98 & $1.01-3.90$ & .047 & 2.69 & $1.64-4.44$ & $<.0001$ \\
\hline $\mathrm{T} 4$ & $10(3)$ & $14(2)$ & & 3.95 & $1.60-9.79$ & .003 & 5.51 & $2.93-10.36$ & $<.0001$ \\
\hline Lymph node status & & & 1 & & & & & & \\
\hline NO & $76(21)$ & 380 (53) & & 1 & & & 1 & & \\
\hline $\mathrm{N}+$ & $293(79)$ & $335(47)$ & & 3.86 & $2.94-5.08$ & $<.0001$ & 2.59 & $2.16-3.12$ & $<.0001$ \\
\hline Histology & & & 0 & & & & & & \\
\hline Adenocarcinoma & $306(83)$ & $559(78)$ & & 1 & & & 1 & & \\
\hline Squamous cell carcinoma & $63(17)$ & $157(22)$ & & 1.01 & $0.76-1.35$ & .945 & 1.13 & $0.92-1.38$ & .257 \\
\hline Chemotherapy & & & 0 & & & & & & \\
\hline No & $327(89)$ & $596(83)$ & & 1 & & & 1 & & \\
\hline Yes & $42(11)$ & $120(17)$ & & 0.80 & $0.58-1.11$ & .185 & 1.00 & $0.79-1.26$ & .998 \\
\hline Anastomotic leakage & & & 0 & & & & & & \\
\hline No & $330(89)$ & $662(92)$ & & 1 & & & 1 & & \\
\hline Yes & $39(11)$ & $54(8)$ & & 1.63 & $1.17-2.29$ & .004 & 1.57 & $1.23-2.05$ & $<.0001$ \\
\hline
\end{tabular}

Values were computed using multivariable Cox regression analyses for risk of recurrence and all-cause mortality. Values are $\mathrm{n}(\%)$, unless otherwise indicated. Numbers of patients may not add up to a total of 1085 , owing to missing values. The test of model coefficients (overall score): $\chi^{2}=193 ; \mathrm{df}=10 ; P<.0001$. $H R$, Hazard ratio; $C I$, confidence interval; $S D$, standard deviation; $A S A$, American Society of Anesthesiologists; $I Q R$, interquartile range.

leakages and recurrence. Whether the increased mortality seen in our study can be explained by an increased risk of recurrence is unclear, because only a trend toward an increased number of deaths due to recurrent esophageal cancer was found (Table 2). In contrast to the growing number of reports supporting this connection, a single study by Martin and colleagues ${ }^{13}$ did not find intrathoracic leakage to be associated with all-cause mortality; however, the number of leakages was limited (30 patients).

Most disease recurrence was found to be distant, most likely owing to microscopic metastases or circulating tumor cells at the time of surgery. This observation indicates that the surgical procedure and lymphadenectomy were radically performed; only $9 \%$ had local or loco-regional recurrent disease. Several studies have investigated the pattern of recurrence in patients undergoing gastroesophageal cancer resection, but the identification of leakage as an independent risk factor is novel, and was most likely found because of the large number of patients in our study. Predictors of recurrence identified in the other studies were similar to our findings, yet Dresner and Griffin ${ }^{14}$ additionally found a poor degree of differentiation and of perineural invasion to be predictive factors of recurrence. These pathologic characteristics were not collected in our national database.

A single study has investigated the effect of postoperative complications on disease recurrence after transthoracic esophagectomy for cancer. Lerut and colleagues ${ }^{15}$ demonstrated in 138 patients that presence of medical or surgical postoperative complications significantly increased the risk of recurrence $(\mathrm{HR}=4.53 ; 95 \% \mathrm{CI}$ : 1.37-14.99, $P=.013$ ). However, anastomotic leakage was included in the general variety of postoperative complications and was not found to be an independent risk factor of 
TABLE 2. Clinical and histopathologic characteristics in patients with, versus without, anastomotic leakage

\begin{tabular}{|c|c|c|c|}
\hline Characteristic & Anastomotic leakage $(\mathbf{n}=93)$ & No leakage $(n=992)$ & $P$ value \\
\hline \multicolumn{4}{|l|}{ Gender } \\
\hline Female & $16(17)$ & $209(21)$ & \multirow[t]{2}{*}{.173} \\
\hline Male & $77(83)$ & $783(79)$ & \\
\hline Age $(y)$, mean $( \pm S D)$ & $63( \pm 9)$ & $63( \pm 9)$ & .403 \\
\hline \multicolumn{4}{|l|}{ Smoking } \\
\hline Nonsmoker & $41(44)$ & $443(45)$ & \multirow[t]{2}{*}{.706} \\
\hline Smoker & $44(47)$ & $446(45)$ & \\
\hline \multicolumn{4}{|l|}{ Alcohol consumption (units per wk) } \\
\hline$<14 / 21$ & $74(80)$ & $823(83)$ & \multirow[t]{2}{*}{.266} \\
\hline$>14 / 21$ & $15(16)$ & $122(12)$ & \\
\hline \multicolumn{4}{|l|}{ ASA score } \\
\hline $1+2$ & $65(70)$ & $763(77)$ & \multirow[t]{2}{*}{.188} \\
\hline $3+4$ & $26(28)$ & $225(23)$ & \\
\hline Nodal yield & 19 (IQR: 13-28) & 20 (IQR: 13-27) & .681 \\
\hline \multicolumn{4}{|l|}{ Postoperative tumor stage } \\
\hline T0 & $9(10)$ & $71(7)$ & \multirow[t]{5}{*}{.045} \\
\hline $\mathrm{T} 1$ & $12(13)$ & $125(13)$ & \\
\hline $\mathrm{T} 2$ & $49(53)$ & $398(40)$ & \\
\hline $\mathrm{T} 3$ & $21(23)$ & $371(37)$ & \\
\hline $\mathrm{T} 4$ & $1(1)$ & $23(2)$ & \\
\hline \multicolumn{4}{|l|}{ Lymph node status } \\
\hline N0 & $44(47)$ & $412(42)$ & \multirow[t]{2}{*}{.261} \\
\hline $\mathrm{N}+$ & $48(52)$ & $580(58)$ & \\
\hline \multicolumn{4}{|l|}{ Histology } \\
\hline Adenocarcinoma & $73(78)$ & $792(80)$ & \multirow[t]{2}{*}{.904} \\
\hline Squamous cell carcinoma & $19(20)$ & $201(20)$ & \\
\hline \multicolumn{4}{|l|}{ Chemotherapy } \\
\hline No & $78(85)$ & $845(85)$ & \multirow[t]{2}{*}{.964} \\
\hline Yes & $14(15)$ & $148(15)$ & \\
\hline \multicolumn{4}{|l|}{ Recurrence } \\
\hline No & $54(8)$ & $662(92)$ & \multirow[t]{2}{*}{.092} \\
\hline Yes & $39(11)$ & $330(89)$ & \\
\hline \multicolumn{4}{|l|}{ Location of metastasis } \\
\hline Distant & $29(31)$ & $238(24)$ & \multirow[t]{2}{*}{.749} \\
\hline Local & $10(11)$ & $92(9)$ & \\
\hline Median time to recurrence (wk) & 78 (IQR: 43-140) & 65 (IQR: 37-108) & .219 \\
\hline Death or recurrent disease & $36(39)$ & $310(31)$ & \\
\hline 5-y disease-free survival $(\%)$ & 27 & 39 & .017 \\
\hline
\end{tabular}

recurrence, on its own, presumably owing to the very limited number of patients and leakages (10 patients).

The reason that anastomotic leakage should pose such a risk for poor long-term outcome might be explained by an inflammatory response, generated by a leak. First, mediastinitis, infection in the pleural cavity, and septicaemia might facilitate the metastatic cascade that eventually leads to disease recurrence. ${ }^{16}$ The theory of a general inflammatory response is supported by 2 large and well-designed studies on anastomotic leakage after curative resection for colonic cancer and risk of recurrence. In both studies, anastomotic leakage was independently and negatively associated with both risk of recurrence and disease-free survival. $^{12,16}$
In addition, a recently published, prospective, and randomized phase- 2 study (40 patients) ${ }^{17}$ evaluated the efficacy of ghrelin (a peptide hormone) administration in reducing the duration of systemic inflammatory response syndrome after esophagectomy. The study showed that postoperative levels of C-reactive protein and interleukin6 , and the incidence of complications, were significantly lower in the ghrelin group, compared with the placebo group. That study adds to the growing number of reports contributing to understanding of the mechanism responsible for the association between infection (leakage) and cancer recurrence. $^{18-21}$

Second, the general level of physical performance after an anastomotic leakage may be so poor that postoperative 


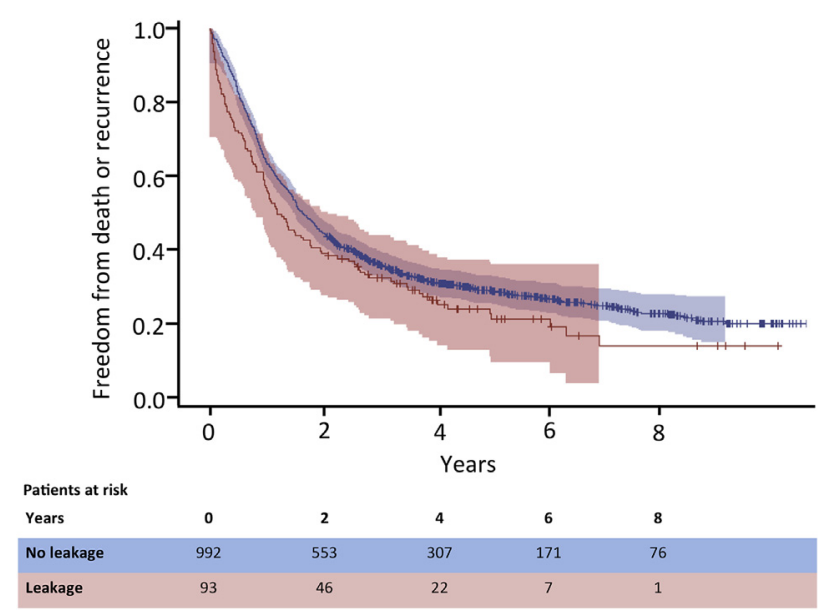

FIGURE 2. Disease-free survival in the 1085 patients, with or without anastomotic leakage, alive 8 weeks after curative gastroesophageal cancer resection with intrathoracic anastomosis $(P=.017)$ and $95 \%$ confidence intervals. Patients were listed as events, at the date of death, or at the date of a positive biopsy showing recurrent esophageal carcinoma. Time zero is 8 weeks after esophagectomy. Patients were censored on the last day of follow-up in the absence of death or recurrence. The red line represents patients who have anastomotic leakage. The blue line represents patients who do not have leakage.

oncologic therapy (the second part of the perioperative regimen) is considerably delayed, or even not possible, and thus the patients are at a survival disadvantage. According to Krarup and colleagues, ${ }^{12}$ cancelled or delayed administration of adjuvant chemotherapy might partly account for increased rates of recurrence seen in patients with leakage after colonic cancer resection. We had data on only those patients who had confirmed oncologic preoperative, perioperative, or adjuvant therapy. Thus, in the present study, we

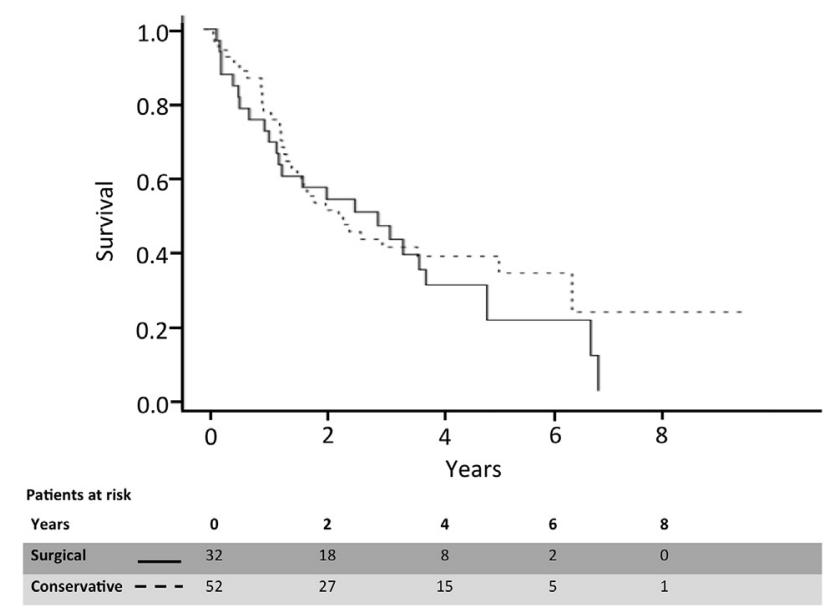

FIGURE 3. Overall survival stratified by reintervention procedure of the leaks $(P=.532)$. Time zero is 8 weeks after esophagectomy. The solid line represents surgical reintervention. The dotted line represents conservative reintervention (stent and/or drainage).
TABLE 3. Leakage management, using surgical reintervention or conservative treatment, and recurrence

\begin{tabular}{cccc}
\hline Treatment & Recurrence (n) & No recurrence (n) & $\boldsymbol{P}$ value \\
\hline $\begin{array}{c}\text { Conservative (stenting } \\
\text { and/or drainage) }\end{array}$ & 25 & 27 & \\
$\begin{array}{c}\text { Surgical (thoracotomy) } \\
\text { S }\end{array}$ & 10 & 22 & .129 \\
\hline
\end{tabular}

Information on leak management was missing in 9 patients.

were unable to determine whether incomplete adjuvant oncologic treatment could explain the increased rate of recurrence seen in patients with leakage. However, of the patients with leakage, $55 \%$ completed the second part of the perioperative program, compared with $80 \%$ of those without leakage. Paired with the observation, in the study by Krarup and colleagues, ${ }^{12}$ that lack of chemotherapy completion is associated with recurrence, this finding adds strength to the circumstantial evidence of this mechanism for the effect of leakage on outcome.

\section{Limitations}

The present study is based on information collected and reported from each center to a nationwide database. Because postoperative follow-up was not standardized, the decision to perform a computed tomography scan and biopsy was based on specific symptomatology, clinical examination, and biochemical findings, in each case. As a result, the number of reported recurrences may be lower than expected, owing to the fact that some patients with recurrence may remain unrecognized because only patients with biopsyproven recurrence were included. No routine surveillance imaging was performed. Theoretically, patients with distant metastases detected using computed tomography scans, ultrasonography, or radiograph shortly after surgery might have been diagnosed with recurrent esophageal carcinoma without biopsy at the local hospital. Although we consider this group minor, these patients will remain undetected with recurrence in the national pathology registry. By excluding patients with recurrence within 8 weeks after surgery, we tried to diminish this bias and to not overestimate the negative effect of leakage on overall survival. We reported a $34 \%$ recurrence rate, similar to that found by Lerut and colleagues, ${ }^{15}$ but lower than the $40 \%$ to $52 \%$ reported by Abate and colleagues, ${ }^{22}$ Dresner and Griffin,,${ }^{14}$ and Mariette and colleagues. ${ }^{23}$ However, assuming that the proportion of unrecognized recurrence is equal in patients with anastomotic leakage and those without, the bias of unrecognized recurrences is considered limited.

A major limitation in the present study is the lack of data on patients with adenocarcinoma that did not complete the second part of the perioperative regimen as part of the trimodal therapy. Greater recurrence after anastomotic leakage may be related to the patients' general weakness and/or reluctance or inability to take prescribed adjuvant therapy. 
The pathologic postoperative stages include patients who were down-staged with perioperative or (adenocarcinoma) chemoradiation (squamous cell), which may carry a different prognosis depending on the degree of downstaging. However, Schmidt and colleagues ${ }^{24}$ failed to show histopathologic regression to be an independent prognostic factor of long-term survival in a subanalysis of 637 curatively resected patients who had gastroesophageal or gastric adenocarcinoma and were treated neoadjuvantly with chemotherapy.

Although anastomotic leakage is difficult to avoid, it is the only 1 of the identified predictors of disease recurrence that can actually be modified. Follow-up programs should be designed to identify those patients who have an increased risk of recurrence: those patients in an advanced stage of cancer on histologic assessment, and those who have experienced anastomotic leakage.

\section{CONCLUSIONS}

The present study demonstrates an increased risk of cancer recurrence after intrathoracic anastomotic leakage in patients who underwent intended curative gastroesophageal cancer resection. This excess long-term mortality seen in the present and previous studies needs further investigation. One possible reason is that the immunologic response gives circulating tumor cells better conditions for growth. Another possibility is that anastomotic leakage requires such a long recovery time that the window of opportunity to receive effective adjuvant therapy may have been missed.

\section{Conflict of Interest Statement}

Authors have nothing to disclose with regard to commercial support.

\section{References}

1. Griffin SM, Shaw IH, Dresner SM. Early complications after Ivor Lewis subtotal esophagectomy with two-field lymphadenectomy: risk factors and management. J Am Coll Surg. 2002; 194:285-97.

2. Lagarde SM, Reitsma JB, Maris AK, van Berge Henegouwen MI, Busch OR, Obertop H, et al. Preoperative prediction of the occurrence and severity of complications after esophagectomy for cancer with use of a nomogram. Ann Thorac Surg. 2008;85:1938-45.

3. Bardini R, Bonavina L, Asolati M, Ruol A, Castoro C, Tiso E. Single-layered cervical esophageal anastomoses: a prospective study of two suturing techniques. Ann Thorac Surg. 1994;58:1087-9; discussion 9-90.

4. Crestanello JA, Deschamps C, Cassivi SD, Nichols FC, Allen MS, Schleck C, et al. Selective management of intrathoracic anastomotic leak after esophagectomy. J Thorac Cardiovasc Surg. 2005;129:254-60.
5. Escofet X, Manjunath A, Twine C, Havard TJ, Clark GW, Lewis WG. Prevalence and outcome of esophagogastric anastomotic leak after esophagectomy in a UK regional cancer network. Dis Esophagus. 2010;23:112-6.

6. Junemann-Ramirez M, Awan MY, Khan ZM, Rahamim JS. Anastomotic leakage post-esophagogastrectomy for esophageal carcinoma: retrospective analysis of predictive factors, management and influence on longterm survival in a high volume centre. Eur J Cardiothorac Surg. 2005;27:3-7.

7. Rutegard M, Lagergren P, Rouvelas I, Lagergren J. Intrathoracic anastomotic leakage and mortality after esophageal cancer resection: a population-based study. Ann Surg Oncol. 2012;19:99-103.

8. Sihvo EI, Luostarinen ME, Salo JA. Fate of patients with adenocarcinoma of the esophagus and the esophagogastric junction: a population-based analysis. Am J Gastroenterol. 2004:99:419-24.

9. Sun Y, Ding B, Zhou N. Stapled anastomosis in esophageal resections with Chinese staplers: a retrospective study of 1965 consecutive cases. Chin Med J. 1998; 111:867-9.

10. Rizk NP, Bach PB, Schrag D, Bains MS, Turnbull AD, Karpeh M, et al. The impact of complications on outcomes after resection for esophageal and gastroesophageal junction carcinoma. J Am Coll Surg. 2004;198:42-50.

11. Kofoed SC, Calatayud D, Jensen LS, Jensen MV, Svendsen LB. Intrathoracic anastomotic leakage after gastroesophageal cancer resection is associated with reduced long-term survival. World J Surg. 2014;38:114-9.

12. Krarup PM, Nordholm-Carstensen A, Jorgensen LN, Harling H. Anastomotic leak increases distant recurrence and long-term mortality after curative resection for colonic cancer: a nationwide cohort study. Ann Surg. 2014;259:930-8.

13. Martin LW, Swisher SG, Hofstetter W, Correa AM, Mehran RJ, Rice DC, et al. Intrathoracic leaks following esophagectomy are no longer associated with increased mortality. Ann Surg. 2005;242:392-9; discussion 9-402.

14. Dresner SM, Griffin SM. Pattern of recurrence following radical oesophagectomy with two-field lymphadenectomy. Br J Surg. 2000;87:1426-33.

15. Lerut T, Coosemans W, Decker G, De Leyn P, Moons J, Nafteux P, et al. Surgical techniques. J Surg Oncol. 2005;92:218-29.

16. Wu Y, Zhou BP. Inflammation: a driving force speeds cancer metastasis. Cell Cycle. 2009; 15:3267-73.

17. Takata A, Takiguchi S, Miyazaki Y, Miyata H, Takahashi T, Kurokawa Y, et al. Randomized phase II study of the anti-inflammatory effect of ghrelin during the postoperative period of esophagectomy. Ann Surg. 2014 [Epub ahead of print].

18. Chuang JY, Huang YL, Yen WL, Chiang IP, Tsai MH, Tang CH. Syk/JNK/AP-1 signaling pathway mediates interleukin-6-promoted cell migration in oral squamous cell carcinoma. Int J Mol Sci. 2014;15:545-59.

19. Li Y, Wang L, Pappan L, Galliher-Beckley A, Shi J. IL-1beta promotes stemness and invasiveness of colon cancer cells through Zeb1 activation. Mol Cancer. 2012;11:87.

20. Lin YM, Chang ZL, Liao YY, Chou MC, Tang CH. IL-6 promotes ICAM-1 expression and cell motility in human osteosarcoma. Cancer Lett. 2013;328: $135-43$.

21. Salim T, Sand-Dejmek J, Sjolander A. The inflammatory mediator leukotriene $\mathrm{D}(4)$ induces subcellular beta-catenin translocation and migration of colon cancer cells. Exp Cell Res. 2014;321:255-66.

22. Abate E, DeMeester SR, Zehetner J, Oezcelik A, Ayazi S, Costales J, et al. Recurrence after esophagectomy for adenocarcinoma: defining optimal follow-up intervals and testing. J Am Coll Surg. 2010;210:428-35.

23. Mariette C, Balon JM, Piessen G, Fabre S, Van Seuningen I, Triboulet JP. Pattern of recurrence following complete resection of esophageal carcinoma and factors predictive of recurrent disease. Cancer. 2003;97:1616-23.

24. Schmidt T, Sicic L, Blank S, Becker K, Weichert W, Bruckner T, et al. Prognostic value of histopathological regression in 850 neoadjuvantly treated oesophagogastric adenocarcinomas. Br J Cancer. 2014;110:1712-20.

Key Words: Leak, gastroesophageal, cancer, survival 